\title{
Analisa Penggunaan K-Gram pada Karakter, Kata dan Kalimat untuk Mendeteksi Kesamaan Dokumen
}

\author{
Ida Widaningrum ${ }^{1)}$, Dyah Mustikasari $^{2)}$, Rizal Arifin $^{3)}$, \& Erika Diyah Cahyani ${ }^{4}$ \\ ${ }^{1,2,4)}$ Program Studi Teknik Informatika, Fakultas Teknik, Universitas Muhammadiyah Ponorogo \\ ${ }^{3)}$ Program Studi Teknik Mesin, Fakultas Teknik, Universitas Muhammadiyah Ponorogo \\ E-mail: iwidaningrum.as@gmail.com,dyah.mustikasari@gmail.com, rizalarifin@gmail.com, erikadyah7@gmail.com
}

\begin{abstract}
Abstrak - Pemanfaatan teknologi digital menjadi sebuah kebutuhan saat ini, salah satu komponennya berupa dokumen. Pendeteksian kesamaan bisa menggunakan berbagi macam cara, diantaranya adalah metode fingerprinting. Fingerprint memiliki prinsip kerja menggunakan teknik hashing dan K-gram. Penelitian ini difokuskan pada model deteksi menggunakan K-gram dengan menggunakan algoritma winnowing dan python sebagai bahasa pemrograman. Pengujian parsing k-gram menggunakan 5 buah k yaitu k=2 k=3 k=4 $\mathrm{k}=5 \mathrm{k}=6$. Hasilnya, parsing karakter mendapatkan presentase lebih besar dari presentase manual karakter. Presentase parsing kata, memiliki presentase yang paling mendekati dari presentase manual. Sedangkan pada kalimat, presentasenya paling rendah dari presentase manual.
\end{abstract}

Kata Kunci: Python, Karakter K-Gram, Kata K-Gram, Kalimat K-Gram, Algoritma Winnowing, Kemiripan Dokumen

\begin{abstract}
The use of digital technology is now a necessity; one of its components is documents. Similarity detection can use a variety of methods, including the fingerprinting method. Fingerprint has a working principle using hashing techniques and K-gram. This research is focused on the detection model using $K$ gram using the winnowing algorithm and python as a programming language. The k-gram parsing test uses 5 $k$ pieces, namely $k=2 k=3 k=4 k=5 k=6$. As a result, the character parsing gets a larger percentage than the manual character percentage. The percentage of word parsing has the closest percentage of the manual percentage. while in sentences, the percentage is the lowest than the manual percentage.
\end{abstract}

Keyword: Python, K-Gram characters, K-Gram words, K-Gram sentences, Winnowing Algorithm, Document Similarity

\section{PENDAHULUAN}

Pemanfaatan teknologi digital menjadi sebuah kebutuhan saat ini, diantaranya berupa dokumen. Dokumen digital sangat mudah untuk diakses. Penelusuran karya-karya dalam bentuk digital, salah satu diantaranya adalah artikel jurnal atau hasil penelitian bisa kita dapatkan melalui internet. Hal ini memungkinkan siapa saja untuk meniru atau mengutip hasil karya orang lain. Penggunaan ide, karya atau tulisan orang lain tanpa seijin orang tersebut dianggap plagiat. Menurut KBBI online, plagiasi adalah meniru pekerjaan orang lain, mengambil karangan orang lain tanpa sepengetahuan penulisnya [1]. Tindakan ini disebabkan oleh tuntutan yang mengharuskan kita menulis, sebagai syarat untuk meraih gelar akademik yang ditempuh atau suatu jenjang jabatan akademik. Hal ini disebabkan dari belum terbiasa atau kurangnya ide untuk membuat penelitian, sehingga terjebak dalam plagiarism. Salah satu cara yang digunakan untuk mengindari plagiat adalah dengan melakukan sitasi, yaitu kita harus mencantumkan sumber kutipan yang kita gunakan [2].

Untuk mengetahui apakah artikel atau tulisan kita buat termasuk kedalam plagiasi atau bukan, biasa digunakan alat untuk mendeteksinya. Sudah banyak alat pendeteksi plagiasi yang ada dipasaran, baik itu yang berbayar ataupun tidak. Metode yang digunakan untuk mendeteksi plagiasi banyak macamnya, salah satu dari metode tersebut adalah fingerprinting. Fingerprinting memiliki prinsip kerja dengan menggunakan teknik hashing. Teknik hashing adalah merubah data menjadi serangkaian bilangan bulat. Jumlah data yang digunakan dinyatakan dengan $\mathrm{K}$ gram [3].

K-gram merupakan salah satu proses yang digunakan dalam text mining dan pengolahan bahasa. K-gram merupakan sekumpulan karakter, kata atau kalimat yang ada pada dokumen dan disaat menghitung k-gram dilakukan dengan menggerakkan DOI: $10.22236 /$ teknoka.v5i.333 
satu string maju ke depan [4]. Berdasarkan KBBI online [1] karakter adalah huruf, angka, ruang atau simbol khusus, kata merupakan satuan Bahasa yang dapat berdiri sendiri, sedangkan kalimat adalah kesatuan ujar yang mengungkapkan suatu konsep pikiran.

Untuk mendeteksi kesamaan dokumen, maka dibuat system dengan teknik Hashing dengan menggunakan Algoritma Winnowing.

Penelitian sebelumnya yang sudah ada adalah, menggunakan 5 (karakter)-gram dalam metode String Matching dengan Algoritma Rabin-Karp untuk mendeteksi plagiasi [5], sedangkan [6] menggunakan Algoritma Winnowing. Penelitian [7] menggunakan 5 (karakter)-gram ini untuk mendeteksi plagiasi dalam Bahasa Inggris, sedangkan [8] menggunakan 9 karakter untuk mendeteksi judul kemiripan skripsi.

Pada penelitian ini akan dibandingkan penggunaan n-gram dalam karakter, kata dan kalimat dengan menggunakan algoritma Winnowing. Diharapkan dari penelitian ini bisa dilihat, manakah yang lebih efektif digunakan dari ketiga pilihan tersebut. Penelitian ini merupakan bagian dari serangkaian penelitian yang didanai oleh Direktorat Riset dan Pengabdian Masyarakat Direktorat Jenderal Penguatan Riset dan Pengembangan Kementerian Riset, Teknologi, dan Pendidikan Tinggi.

\section{LANDASAN TEORI}

Berdasarkan KBBI, plagiasi merupakan pengambilan karya orang lain dan menjadikannya seolah-olah karya sendiri [1]. K-gram merupakan salah satu proses yang digunakan dalam text mining dan pengolahan bahasa. K-gram merupakan sekumpulan karakter, kata atau kalimat yang ada pada dokumen dan disaat menghitung k-gram dilakukan dengan menggerakkan satu string maju ke depan [4]. Dalam K-Gram karakter, karakter akan dikumpulkan kedalam kelompok yang terdiri dari sejumlah $\mathrm{k}$ (misalnya uni, bi, tri dan seterusnya). Misalnya dalam kata "BELAJAR", akan didapatkan k-gram karakter sebagai berikut.

Unigram: B, E, L, A, J, A, R

Bigram:_B, BE, EL, LA, AJ, JA, R_

Trigram: _BE, BEL, ELA, LAJ, AJA, JAR, AR_, R

$\overline{\mathrm{K}}$-Gram kata, sebagai contoh terdapat sebuah kalimat

"Kemarin aku beli sepeda baru keren". Akan didapatkan k-gram kata sebagai berikut.

Unigram: kemarin, aku, beli, sepeda, baru, keren.
Bigram: kemarin aku, aku beli, beli sepeda, sepeda baru, baru keren.

Trigram: kemarin aku beli, sepeda baru keren.

K-Gram kalimat Terdapat sebuah paragraf "Universitas Muhammadiyah Ponorogo adalah universitas berintegritas. Mempunyai komitmen tinggi untuk menjadi lembaga pendidikan dan pelatihan kejuruan berstandar nasional / internasional, berwawasan unggul, kompetitif dan pofesional dengan berdasarkan imtaq. Menjadi universitas yang unggul dalam penguasaan ilmu pengetahuan, teknologi, dan seni berdasarkan nilai-nilai islami". Didapatkan kgram kalimat sebagai berikut.

Unigram: universitas muhammadiyah ponorogo adalah universitas berintegritas; mempunyai komitmen tinggi untuk menjadi lembaga pendidikan dan pelatihan kejuruan berstandar nasional / internasional, berwawasan unggul, kompetitif dan pofesional dengan berdasarkan imtaq; menjadi universitas yang unggul dalam penguasaan ilmu pengetahuan, teknologi, dan seni berdasarkan nilainilai islami.

Rolling hash adalah salah satu metode dengan teknik hash, digunakan untuk menemukan nilai hash dari rangkaian grams. Rolling hash merupakan fitur yang menghitung nilai hash tanpa mengulangi seluruh string. Nilai hash adalah nilai numerik yang dibentuk dari kode ASCII [9].

Algoritma Winnowing merupakan salah satu algoritma text mining dengan menggunakan dokumen fingerprint yang kemudian memakai teknik hashing dalam mencocokkan dua atau lebih dokumen. Teknik hashing sendiri digunakan untuk mengubah setiap karakter dalam dokumen menggunakan ASCII. Fungsi hash yang digunakan Winnowing adalah Rolling Hashing [10].

Koefisien Jaccard digunakan untuk menghitung kemiripan himpunan string yang nilai hashnya telah dihitung, koefisien Jaccard ini dapat mengukur prosentase kemiripan teks [11].

\section{METODOLOGI PENELITIAN}

Penghitungan Data menggunakan algoritma Winnowing.

a. Pembuangan tanda baca, spasi dan symbol-simbol seperti =,\#, \%, \&, (, ), -,,,\$, @, !, /,”,

b. Pembentukan rangkaian metode K-Gram berupa karakter, kata, dan kalimat. Dan menggunakan 5 jenis $K$ yaitu yaitu $K=2 K=3 K=4 K=5 K=6$.

c. Perhitungan Fungsi Hash untuk tiap k-gram. Rolling hash adalah salah satu metode dari teknik hashing untuk mencari nilai hash dari rangkaian 
grams seluruh karakter. Nilai hash adalah angka yang dibentuk dari kode ASCII.

d. Rolling hash adalah fungsi yang menghitung nilai hash tanpa mengulangi seluruh string

$H(c h)=c_{1} * b^{(k-1)}+c_{2} * b^{(k-2)}+\cdots+c_{k} * b^{(k-k)}$

Keterangan:

$\mathrm{c}=$ nilai ascii karakter

$\mathrm{b}=$ basis (bilangan prima)

$\mathrm{k}=$ banyak karakter

e. Membagi ke dalam Window tertentu dari Nilai Hash

f. Pemilihan Fingerprint dari Setiap Window. Langkah terakhir yaitu memilih nilai terkecil dari setiap window untuk dijadikan dokumen fingerprint

g. Similaritas Jaccard dapat digunakan sebagai menghitung kemiripan dari kumpulan string yang telah dihitung nilai hash dan dapat mengukur prosentase kemiripan teks

Berikut ini rumus persamaan Jaccard Coefficient [8]

$$
\text { Similarity }=\frac{\text { Jwhiah fingerprint sama }}{\text { Total seluruh fingerprint }} x 100
$$

Desain dan metode penelitian yang digunakan ditampilkan pada gambar 1 .

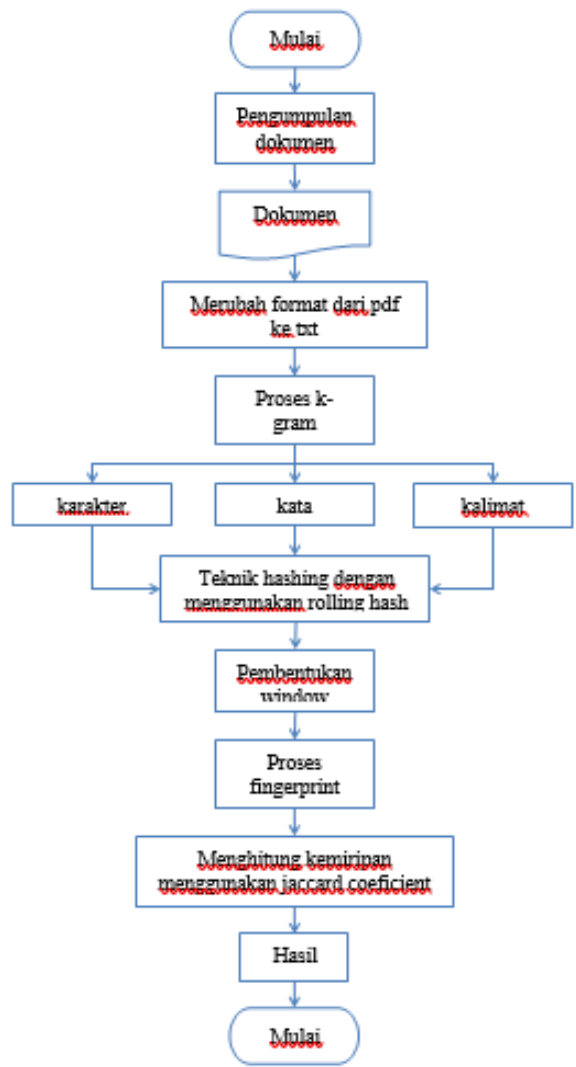

Gambar 1 Alur penghitungan K-gram menggunakan Algoritma Winnowing

\section{HASIL DAN PEMBAHASAN}

Berikut akan sedikit dijelaskan contoh penerapan k-gram pada parsing karater pada algoritma winnowing:

a. Langkah pertama adalah penghilangan karakter yang tidak diperlukan, seperti simbol, tanda baca, tanda spasi, mengubah huruf besar menjadi kecil, dan simbol-simbol selain huruf a sampai z.

b. Langkah kedua adalah parsing karakter menggunakan $\mathrm{k}=6$

Untuk kalimat I terbentuklah rangkaian gram sebagai berikut :

univer nivers iversi versit ersita rsitas............ ponoro onorog norogo

Untuk kalimat II terbentuklah rangkaian gram sebagai berikut :

univer nivers iversi versit ersita rsitas

.....madiun

c. Langkah ketiga selanjutnya mencari nilai Hash dari setiap gram yang dibentuk. Sebagai contoh ditentukan nilai basisnya adalah 3 dan gram nya adalah 6.

Perhitungan untuk kalimat I:

$\mathrm{H}_{\text {(univer) }}=\operatorname{ascii}(\mathrm{u}) * 3^{(5)}+\operatorname{ascii}(\mathrm{n}) * 3^{(4)}+\operatorname{ascii}(\mathrm{i}) * 3^{(3)}$

$+\operatorname{ascii}(\mathrm{v}) * 3^{(2)}+\operatorname{ascii}(\mathrm{e}) * 3^{(1)}+\operatorname{ascii}(\mathrm{r}) * 3^{(0)}$

$=117 * 243+110 * 81+105 * 27+118 * 9+101 * 3$

$+114 * 1$

$=28.431+8.910+2.835+1.062+303+114$

$=41.655$

dan seterusnya, sehingga diperoleh perhitungan sebagai berikut:

416553978739276

Perhitungan untuk kalimat II:

$\mathrm{H}_{\text {(univer) }}=\operatorname{ascii}(\mathrm{u}) * 3^{(5)}+\operatorname{ascii}(\mathrm{n}) * 3^{(4)}+\operatorname{ascii}(\mathrm{i}) * 3^{(3)}$

$+\operatorname{ascii}(\mathrm{v}) * 3^{(2)}+\operatorname{ascii}(\mathrm{e}) * 3^{(1)}+\operatorname{ascii}(\mathrm{r}) * 3^{(0)}$

$=117 * 243+110 * 81+105 * 27+118 * 9+101 * 3$

$+114 * 1$

$=28.431+8.910+2.835+1.062+303+114$

$=41.655$

Dan seterusnya, sehingga diperoleh perhitungan sebagai berikut:

416553978739276

d. Setelah mendapatkan nilai hash dari proses Rolling Hash, selanjutnya adalah membagi nilai-nilai hash tersebut menurut window:

Untuk kalimat I, windownya sebagai berikut:

(41655 39787392764139938272$)$

$\left(\begin{array}{lllll}\ldots . . . & \ldots . . & \ldots . . & \ldots . . . & \ldots . . .\end{array}\right)$

Kemudian untuk kalimat 2 windownya adalah sebagai berikut: 


\section{$\left(\begin{array}{llll}41655 & 397873927641399 & 38272\end{array}\right)$}

$\left(\begin{array}{lllll}\ldots . . . & \ldots . . & \ldots . . . & \ldots . . . & \ldots . . .\end{array}\right)$

e. Langkah selanjutnya, memilih nilai hash terkecil dengan posisi paling kanan dari setiap window untuk dijadikan fingerprint. Berikut ini adalah nilai fingerprint yang didapat:

Untuk Kalimat I fingerprint yang didapat adalah:

Jumlah fingerprint: 5

(38272, 37291, 36621, 35990, 36459)

Untuk Kalimat II fingerprint yang didapat adalah:

Jumlah fingerprint: 4

$(38272,37180,36667,36351)$

f. Kemudian selanjutnya adalah menghitung prosentase kemiripan dengan menggunakan persamaan jaccard similarity coefficient .

Fingerprint sama: 1

Fingerprint berbeda: 7

$$
\begin{aligned}
\text { Similarity }= & \frac{\text { Jumlah fingerprint sama }}{\text { Totalseluruh fingerprint }} \times 100= \\
& =\frac{1}{8} \times 100 \%=\mathbf{1 2}, \mathbf{5} \%
\end{aligned}
$$

Jadi, hasil Similaritasnya adalah $12.5 \%$

\section{Contoh penerapan k-gram pada parsing kata pada} algoritma winnowing:

a. Pertama, menghilangkan karakter yang tidak diperlukan, seperti simbol, tanda baca, tanda spasi, mengubah huruf besar menjadi kecil, dan simbolsimbol selain huruf a sampai $z$.

b. Pembentukan rangkaian gram,

Untuk kalimat I, terbentuk rangkaian gram sebagai berikut:

sebanyakmahasiswa

mahasiswauniversitas universitasmerdeka merdekaunmer unmermadiun madiunakan akanmengikuti mengikutikuliah kuliahkerja kerjanyata nyatakkn kkndi dikabupaten kabupatenmadiun madiunmulai mulaijanuari januarihingga hinggafebruari februariacara acarapelepasan pelepasanpemberangkatan pemberangkatanpeserta pesertakkn kkndi digedung gedunggraha grahasamiarto samiartounmer unmerkota kotamadiun

Untuk kalimat II, terbentuk rangkaian gram sebagai berikut:

mahasiswauniversitas universitasmuhammadiyah muhammadiyahponorogo ponorogopada padahari harikamis kamisdi diberangkatkan berangkatkanoleh olehrector rectorumpo umpountuk untukkkn kknkuliah kuliahkerja kerjanyata nyatainternasional internasionalke kekamboja kambojaphilipina philipinadan danmalaysia malaysia c. Proses Rolling Hash, untuk menghasilkan nilai hash dari setiap gram yang dibentuk. Contohnya, ditentukan nilai basis $=3$ dan gram $=2$.

$\mathrm{H}$ (mahasiswauniversitas)

$=\operatorname{ascii}(\mathrm{m})+\operatorname{ascii}(\mathrm{a})+\operatorname{ascii}(\mathrm{h})+\operatorname{ascii}(\mathrm{a})+\operatorname{ascii}(\mathrm{s})+$ $\operatorname{ascii}(\mathrm{i})+\operatorname{ascii}(\mathrm{s})+\operatorname{ascii}(\mathrm{w})+\operatorname{ascii}(\mathrm{a})+\operatorname{ascii}(\mathrm{u})+$ $\operatorname{ascii}(\mathrm{n})+\operatorname{ascii}(\mathrm{i})+\operatorname{ascii}(\mathrm{v})+\operatorname{ascii}(\mathrm{e})+\operatorname{ascii}(\mathrm{r})+$ $\operatorname{ascii}(\mathrm{s})+\operatorname{ascii}(\mathrm{i})+\operatorname{ascii}(\mathrm{t})+\operatorname{ascii}(\mathrm{a})+\operatorname{ascii}(\mathrm{s})$

$=(109+97+104+97+115+105+115+119+97)$

$* 3^{1}+(117+110+105+118+101+114+115+$

$105+116+97+115) * 3^{0}$

$=958 * 3^{1}+1213 * 3^{0}=4.087$

dan seterusnya, sehingga diperoleh perhitungan sebagai berikut :

40874908469030551638

Perhitungan untuk kalimat II:

$\mathrm{H}_{\text {(sebanyakmahasiswa) }}$

$=\operatorname{ascii}(\mathrm{s})+\operatorname{ascii}(\mathrm{e})+\operatorname{ascii}(\mathrm{b})+\operatorname{ascii}(\mathrm{a})+\operatorname{ascii}(\mathrm{n})+$ $\operatorname{ascii}(y)+\operatorname{ascii}(a)+\operatorname{ascii}(k)+\operatorname{ascii}(m)+\operatorname{ascii}(a)+$ $\operatorname{ascii}(\mathrm{h})+\operatorname{ascii}(\mathrm{a})+\operatorname{ascii}(\mathrm{s})+\operatorname{ascii}(\mathrm{i})+\operatorname{ascii}(\mathrm{s})+$ $\operatorname{ascii}(\mathrm{w})+\operatorname{ascii}(\mathrm{a})$

$=(115+101+98+97+110+121+97+107) * 3^{1}+$ $(109+97+104+97+115+105+115+119+$ $97) * 3^{0}$

$=846 * 3^{1}+958 * 3^{0}=3496$

Dan seterusnya, sehingga diperoleh perhitungan sebagai berikut:

$34964087 \quad 43682738 \quad 2291$

d. Bagi nilai-nilai hash tersebut menurut window.

e. Pilih nilai hash terkecil dengan posisi paling kanan dari setiap window, untuk dijadikan fingerprint.

Berikut adalah nilai fingerprint yang didapat

Untuk Kalimat I.

Jumlah fingerprint: 6

[2874, 1638, 1793, 1914, 1610, 1349]

Untuk Kalimat II.

Jumlah fingerprint: 11

$[2291,2206,2116,1947,1177,1570,2354,2465$, 1249, 1931, 1914]

Kemudian selanjutnya adalah menghitung prosentase kemiripan dengan menggunakan persamaan jaccard similarity coefficient .

Fingerprint sama: 1

Fingerprint berbeda: 16

$$
\begin{aligned}
\text { Similarity } & =\frac{\text { Jumlah fingerprint sama }}{\text { Totalseluruh fingerprint }} \times 100= \\
& =\frac{1}{17} \times 100 \%=5,8 \%
\end{aligned}
$$

Jadi, hasil Similaritasnya adalah 5.8\% 
Contoh penerapan k-gram pada parsing kalimat pada algoritma winnowing:

a. Sama seperti sebelumnya, pertama hilangkan karakter yang tidak diperlukan, seperti simbol, tanda baca, tanda spasi. Ubah huruf besar menjadi kecil.

b. Kedua, parsing kalimat menggunakan $\mathrm{k}=2$

c. Langkah ketiga, proses Rolling Hash untuk menghasilkan nilai dari setiap gram yang dibentuk. Sebagai contoh ditentukan nilai basisnya adalah 3 dan gram nya 2.

Perhitungan untuk kalimat I dan diperoleh perhitungan sebagai berikut:

272563864450133

Perhitungan untuk kalimat II dan diperoleh perhitungan sebagai berikut:

25722386444701858241

d. Setelah mendapatkan nilai hash dari proses Rolling Hash maka langkah keempat selanjutnya adalah membagi nilai-nilai hash tersebut menurut window.

Untuk kalimat I, windownya sebagai berikut:

(27256 38644 50133)

(38644 5013364471$)$

$\left(\begin{array}{llll}\ldots . . . & \ldots . . . & \ldots . . .\end{array}\right)$

Kemudian untuk kalimat 2 windownya adalah sebagai berikut:

(27256 3864450133 )

(38644 4701858241$)$

(..........................)

e. Langkah selanjutnya adalah memilih nilai hash terkecil dengan posisi paling kanan dari setiap window untuk dijadikan fingerprint (penanda). Berikut ini adalah nilai fingerprint yang didapat

Untuk Kalimat I fingerprint yang didapat adalah: Jumlah fingerprint: 8

Fingerprint dokumen pertama:

[27256, 38644, 50133, 56613, 26367, 20050, 13400, 23866]

Untuk Kalimat II fingerprint yang didapat adalah:

Jumlah fingerprint: 8

Fingerprint dokumen kedua:

[25722, 38644, 47018, 56613, 26367, 26731, 23952, 25807]

Kemudian selanjutnya adalah menghitung prosentase kemiripan dengan menggunakan persamaan jaccard similarity coefficient.

Fingerprint sama: 3

Fingerprint berbeda: 10
Similarity $=\frac{\text { Jumlah fingerprint sama }}{\text { Total seluruh fingerprint }} \times 100=\frac{3}{13} \times 100 \%=23,1 \%$

Jadi, hasil Similaritasnya adalah $23.1 \%$

\section{Analisis 3 Parsing K-Gram}

Pengujian parsing k-gram dengan menggunakan 5 buah $\mathrm{k}$ yaitu $\mathrm{k}=2 \mathrm{k}=3 \mathrm{k}=4 \mathrm{k}=5 \mathrm{k}=6$. $\mathrm{k}$-gram pada karakter, kata, kalimat dengan ketentuan window $=5$ dan basis = 3 dengan dokumen uji adalah uji.py dan dokumen pembanding.py. Kemudian dilihat selisih dari presentase perhitungan manual berdasarkan setiap parsing k-gram.

Hasil parsing karakter, dokumen 1 memiliki total 17.768 karakter. Dokumen 2 adalah dokumen yang sama, namun dihilangkan beberapa kalimat untuk membedakan isi dari dokumen sehingga dokumen 2 memiliki total 15.123 karakter. Menurut perhitungan manual prosentase kemiripan antar dua dokumen tersebut seharusnya menghasilkan 15,123/17,768 x $100 \%=85,11 \%$.

Pada parsing kata, dokumen 1 memiliki total 2.802 kata, dan dokumen 2 adalah dokumen yang sama namun dihilangkan beberapa kalimat untuk membedakan isi dari dokumen sehingga dokumen 2 memiliki total 2.406 kata. Menurut perhitungan manual prosentase kemiripan antar dua dokumen tersebut seharusnya menghasilkan 2,406/2,802 x $100 \%=85,87 \%$.

Pada parsing kalimat, dokumen 1 memiliki total 200 kalimat dan dokumen 2 adalah dokumen yang sama namun dihilangkan beberapa kalimat untuk membedakan isi dari dokumen sehingga dokumen 2 memiliki total 171 kalimat. Menurut perhitungan manual prosentase kemiripan antar dua dokumen tersebut seharusnya menghasilkan 200/171 x 100\%= $85,5 \%$.

Hasil analisis ketiga parsing k-gram dapat dilihat pada tabel 1.

Tabel 1 Hasil analisis parsing k-gram

\begin{tabular}{llllcl}
\hline No. & Parsing & K- & Hasil & $\begin{array}{c}\text { Hasil } \\
\text { manual }\end{array}$ & Selisih \\
\hline 1. & karakter & ii & $97.7 \%$ & 85.11 & $12.59 \%$ \\
2. & & iii & $96.8 \%$ & $\%$ & $11.69 \%$ \\
3. & & iiii & $97.5 \%$ & & $12.39 \%$ \\
4. & & iiiii & $93.8 \%$ & & $8.69 \%$ \\
5. & & iiiiii & $90.0 \%$ & & $4.89 \%$ \\
\hline 6. & Kata & ii & $84.8 \%$ & 85.87 & $-1.07 \%$ \\
7. & & iii & $79.8 \%$ & $\%$ & $-6.07 \%$ \\
8. & & iiii & $77.0 \%$ & & $-8.87 \%$ \\
9. & & iiiii & $75.0 \%$ & & $-10.87 \%$ \\
10. & & iiiiii & $73.2 \%$ & & $-12.67 \%$ \\
\hline
\end{tabular}

Seminar Nasional TEKNOKA ke - 5, Vol. 5, 2020 ISSN No. 2502-8782 


\begin{tabular}{|c|c|c|c|c|c|}
\hline 11. & Kalimat & ii & $58.7 \%$ & $85.5 \%$ & $-26.8 \%$ \\
\hline 12. & & iii & $55.4 \%$ & & $-30.1 \%$ \\
\hline 13. & & iiii & $55.3 \%$ & & $-30.2 \%$ \\
\hline 14. & & iiiii & $47.7 \%$ & & $-37.8 \%$ \\
\hline 15. & & iiiiii & $41.6 \%$ & & $-43.9 \%$ \\
\hline
\end{tabular}

\section{SIMPULAN}

Hasil parsing karakter mendapatkan presentase yang lebih besar dari presentase manual karakter. Walaupun menggunakan 5 buah $\mathrm{k}$, hasil menunjukan presentase yang cukup besar pada parsing karakter dari pada parsing kata dan kalimat. Presentase pada parsing kata memiliki presentase yang paling mendekati hasil presentase manual. Sedangkan pada kalimat, hasil presentasenya paling rendah dari pada hasil presentase manual.

\section{KEPUSTAKAAN}

[1] Kemdikbud. (2016, 22 Januari 2020). KBBI online.

[2] P. Istiana, "Membuat Sitasi dan Daftar Pustaka," in "Materi Pelatihan Kursus Pelatihan Instruktur Literasi Informasi. ," Universitas Padjajaran Bandung, Universitas Sanata Dharma, Yogyakarta 2013, vol. 27 December 2014.

[3] I. Widiastuti, C. Rahmad, and Y. Ariyanto, "Aplikasi Pendeteksi Kemiripanpada Dokumen Menggunakan Algoritma Rabin Karp," Jurnal Informatika Polinema, vol. 1, no. 2, pp. 13-13, 2015.

[4] S. Sunardi, A. Yudhana, and I. A. Mukaromah, "Implementasi Deteksi Plagiarisme Menggunakan Metode N-Gram Dan Jaccard Similarity Terhadap Algoritma Winnowing," 2018.
A. Prastyanti and S. N. Endah, "Sistem deteksi kemiripan kata pada dua dokumen menggunakan algoritma Rabin-Karp," Universitas Diponegoro, 2014.

[6] R. Y. Dillak, F. Laumal, and L. J. Kadja, "Sistem Deteksi Dini Plagiarisme Tugas Akhir Mahasiswa Menggunakan Algoritma Ngrams dan Winnowing," Jurnal Ilmiah Flash, vol. 2, no. 1, pp. 12-18, 2016.

[7] A. Kurniawati and I. Wicaksana, "Perbandingan pendekatan deteksi plagiarism dokumen dalam bahasa inggris," in Proceeding, Seminar Ilmiah Nasional Komputer dan Sistem Intelijen (KOMMIT 2008), 2008: Gunadarma University.

[8] N. Alamsyah, "Perbandingan Algoritma Winnowing Dengan Algoritma Rabin Karp Untuk Mendeteksi Plagiarisme Pada Kemiripan Teks Judul Skripsi," Technologia: Jurnal Ilmiah, vol. 8, no. 3, pp. 124-134, 2017.

[9] B. Zaman, E. Hariyanti, and E. Purwanti, "Sistem Deteksi Bahasa pada Dokumen menggunakan N-Gram," Multinetics, vol. 1, no. 2, pp. 21-26, 2015.

[10] A. Radili and S. Sanjaya, "Penerapan Metode Winnowing Fingerprint dan Naive Bayes untuk Pengelompokan Dokumen," Jurnal CoreIT: Jurnal Hasil Penelitian Ilmu Komputer dan Teknologi Informasi, vol. 3, no. 2, pp. 69-75, 2018.

[11] S. Niwattanakul, J. Singthongchai, E. Naenudorn, and S. Wanapu, "Using of Jaccard coefficient for keywords similarity," in Proceedings of the international multiconference of engineers and computer scientists, 2013, vol. 1, no. 6, pp. 380-384. 